\title{
Risk factors for breast cancer for women in Punjab, Pakistan: Results from a case-control study
}

\author{
Ghausia Masood Gilani
}

Institute of Statistics, University of the Punjab

Q. A. Campus, Lahore, Pakistan

Shahid Kamal

Institute of Statistics, University of the Punjab

Q. A. Campus, Lahore, Pakistan

Syed Aamir Masood Gilani

Institute of Statistics, University of the Punjab

Q. A. Campus, Lahore, Pakistan

\begin{abstract}
Over the last three decades an increase in the incidence of breast cancer has been observed in the previously low-risk Asian countries. This study is designed to determine the risk factors of breast cancer for Pakistani women as little information exists in this regard. A case-control study of 564 female breast cancer cases diagnosed at the two cancer hospitals at Lahore (INMOL and SKMCH) during the time period Jan 1, 1998 to Dec 31, 1998 was carried out. Four hundred and forty eight women aged 24-80 years out of 564 cases were complete with respect to defined criteria and were eligible for the study. Population-based controls were selected to match for age of cases in the ratio 1:2. The data were analyzed considering 'all women' and then separate analyses were done for 'premenopausal' and 'postmenopausal women'. Women with family history of breast cancer, history of consanguineous marriage, smoking and high BMI $(\geq 28)$ are at increased risk of breast cancer for all three groups. Early menarche ( $<13$ years) was not a risk factor for this study. Late age at menopause (>45 years) was a strong determinant of breast cancer. Higher number of full-term pregnancies $(>3)$ was protective for 'all women' and 'premenopausal women' but in case of 'postmenopausal women' the poor with higher number of pregnancies were significantly protected. Late age at first FTP (>25 years) is a significant risk factor for postmenopausal women.
\end{abstract}

Key words: OR: Odds Ratio:

FTP: Full Term Pregnancy

C.I.: Confidence Interval

BMI: Body Mass Index

\section{Introduction}

The incidence of breast cancer in women has globally increased. Even in previously low-risk developing Asian countries, the incidence of breast cancer has increased sharply over the past three decades (Coleman et al., 1993). The cancer data in Pakistan show that breast cancer is hitting the largest proportion of the population (Yousuf \& Jafarey, 1985). Among females breast is the most common site of cancer, accounting for one third of female cancer (AgeStandardized Rate $=51.7$ ). Bhurgri et al., 2000 reported the highest incidence of breast cancer for any Asian population except Jews in Israel. 
Address correspondence to: Ghausia Masood Gilani, Ph.D., Institute of Statistics, University of the Punjab, Q. A. Campus, Lahore. Email: gilani_pu@hotmail.com The risk factors for breast cancer vary with respect to geographic characteristics and life-style-related habits of a community. A significant increase in risk has been associated with early menarche, late age at menopause, late age at the first full term pregnancy and three or fewer full-term pregnancies have a significantly increased risk of breast cancer (Lai et al., 1996; Talamini et al., 1996) and positive history of breast cancer in the family (Gilani and Kamal., 2004; Gilani, 2004; Collaborative Group on Hormonal Factors in Breast Cancer, 2001; Colditz et al., 1996; Romieu et al., 1996; Negri et al., 1988; Helmrich et al., 1983). In some studies little or no evidence of association was observed between age at menarche and breast cancer incidence for premenopausal women (Choi et al., 1978; Helmrich et al., 1983; Negri et al., 1988; Gilani and Kamal., 2004), though for the postmenopausal women an increasing risk with earlier age at menarche was observed (Choi et al., 1978). Some studies have indicated a protective effect for late menarche (Hsieh et al., 1990; Kvale \& Heuch, 1988; Brinton et al., 1988). A strong trend of increasing breast cancer risk with increasing age at menopause was reported in some studies (Talamini et al., 1996; La Vecchia et al., 1992; Negri et al., 1988).

High body mass index (BMI) has also been shown to be positively associated with an increased risk of breast carcinoma in many studies (Zhu et al., 2005; Huang et al., 1997; Ballard-Barbash \& Swanson, 1996; Ramon et al., 1996). Increased body mass index is observed to be protective before menopause (Kampart et al., 1988) but detrimental after menopause (Kampart et al., 1988; Negri et al., 1988) but the reports are inconclusive. The higher social class standing is associated with an elevated risk of breast cancer among women over age 40 (Kreiger, 1990). In this paper a case-control study design has been used to identify the risk factors for breast cancer in parous Pakistani women. We have also attempted the study by menopausal status. The risk factors investigated included age at menarche, age at menopause, family history of breast cancer, socio-economic status consanguineous marriage, history of smoking, age at first full term pregnancy, number of live-births and body mass index (BMI).

\section{Material and Methods:}

Female breast cancer cases were obtained from two major cancer hospitals located in Lahore, Pakistan, namely: the Institute of Nuclear Medicines of Oncology, Lahore (INMOL) and Shaukat Khanum Memorial Cancer Hospital (SKMCH) Lahore, Pakistan. The individuals are referred to these hospitals from 
all over rural and urban areas of Punjab. The two hospitals jointly represented cancer patients from all the socio-economic levels. Patients who were registered with diagnosed breast cancer at either hospital for the first time between 1 January 1998 and 31 December 1998 were interviewed. Only those women, who had ever delivered, were eligible for this study. Five hundred and sixty four female breast cancer cases were diagnosed at the two hospitals during this period. Of these four hundred and forty eight breast cancer cases aged 24 to 80 years matched the criteria of study. These were matched for age with populationbased controls in the ratio 1:2. For this case-control study 896 controls were selected as follows. Two villages were selected to represent the rural population (Shah De Khui and Manga Mandi) and two cities were selected to represent the urban population (Lahore, a metropolitan city and Gujranwala, an industrial city). Then areas were randomly selected and individual houses were selected according to convenience. One control from one house was interviewed for the study. The women who had ever delivered and were between ages 24-80 years were considered as eligible controls for this study. Cases and controls were interviewed in hospitals and residences respectively. Verbal consent was obtained from the participants prior to their interview.

An interview schedule was prepared to obtain data on personal characteristics (age, marital status; socio-economic status), menstrual and reproductive factors, anthropometrics (height, weight), family history of breast cancer, history of smoking, and consanguineous marriage for both cases and controls. All the cases and controls were interviewed by the same enumerators to reduce the effect of interviewer bias.

Information was collected on menstrual factors [age at menarche, menopausal status, age at menopause] and reproductive factors (age at first full term pregnancy, number of full term pregnancies). Some questions about the family history of breast cancer, history of smoking, and the history of being in a consanguineous marriage were also included in the questionnaire. Height in centimeters and weight in kilograms were measured physically with the consent of the respondents. Weights were rounded to the nearest kilogram and heights were rounded to the nearest centimeter. Body Mass index was calculated as Quetelet's Index, where weight in kilograms is divided by the square of height in meters. Family history of breast cancer was coded as positive if at least one relative (up to third-degree) of the respondent had developed breast cancer. For consanguineous marriage, information was collected on whether women were married to a first cousin or to some other relative within their biraderi (extended 
family, literally meaning brotherhood) or to some person outside the biraderi. Positive history of smoking (ex-smoking or current smoking) was coded as 'Ever'. Socio-economic status was determined by combining the information on income and occupation of self or husband. Those who had some regular formal source of income with an income of rupee six thousands or below were coded as 'poor' and otherwise coded as 'not poor'. Number of pregnancies was the number of full-term pregnancies. Women who had stopped menstruating for one year or more were considered postmenopausal. Out of 448 cases, 260 cases and out of 896 controls 533 controls were in postmenopausal group. Subjects were stratified into four age groups ( $<40$ years, $40-49,50-59,60+$ years).

Women who had delivered were analyzed in multiple logistic regression models, using unconditional analysis. The t-test was used to compare the cases and controls for each variable. Multiple logistic regression models were used to estimate the odds ratios (ORs) and their 95\% confidence intervals (Cls) after adjusting for potential confounders (Breslow and Day; 1980). The data were analysed using the statistical packages SPSS v12.0 and Epilnfo, 2000 v1.1. For quantitative variables of the study, cut-points were decided by quartile analysis of each variable. Multiple logistic regression models were used to analyze dataset comprising all women and then separately by menopausal status. These models were developed to adjust for confounding influences.

Descriptive analysis:

The characteristics of the study population are shown in Table 1.

Majority of the cases and controls were postmenopausal. The percentage of postmenopausal women was 58.0 and 59.5 for cases and controls respectively. A high percentage of both the groups were poor (62.7\% cases and $64.4 \%$ controls). Family history of breast cancer was positive for only $14.3 \%$ cases and $6.8 \%$ controls. The prevalence of smoking was very low for the two groups. The percentage of cases with consanguineous marriage (59.2) was observed to be much higher than that of controls (39.5). Early menarche ( $<13 \mathrm{yrs})$ was reported by $14.5 \%$ of cases and $23.2 \%$ of controls. Most of the women for both the groups had their age at first birth $\leq 25$ years. Fewer cases had more than three full term pregnancies as compared to controls. High BMI ( $\geq 28)$ was found for $40.4 \%$ cases and $23.2 \%$ controls. A high percentage of controls (65.4) had an early menopause ( $\leq 45 y r s)$ whereas this percentage was 47.5 for cases. 
Table 1: Characteristics of Study $\mathrm{P} \geq 0$ pulation

\begin{tabular}{|c|c|c|c|c|}
\hline Characteristics & $\begin{array}{l}\text { Total (1344) } \\
\text { No. (\%) }\end{array}$ & $\begin{array}{c}\text { Cases (448) } \\
\text { No. (\%) }\end{array}$ & $\begin{array}{c}\text { Controls (896) } \\
\text { No. (\%) }\end{array}$ & $P$ value \\
\hline \multicolumn{5}{|l|}{ Age (yrs) } \\
\hline $\begin{array}{l}\text { Below } 40 \\
40-49 \\
50-59 \\
60 \& \text { above }\end{array}$ & $\begin{array}{l}348(25.9) \\
413(30.7) \\
343(25.5) \\
240(17.9)\end{array}$ & $\begin{array}{r}116(25.9) \\
138(30.8) \\
114(25.4) \\
80(17.9)\end{array}$ & $\begin{array}{r}232(25.9) \\
275(30.7) \\
229(25.6) \\
60(17.9)\end{array}$ & \\
\hline $\begin{array}{l}\text { Menopausal Status } \\
\text { Premenopausal } \\
\text { postmenopausal }\end{array}$ & $\begin{array}{l}551(41.0) \\
793(59.0)\end{array}$ & $\begin{array}{l}188(42.0) \\
260(58.0)\end{array}$ & $\begin{array}{l}363(40.5) \\
533(59.5)\end{array}$ & 0.610 \\
\hline $\begin{array}{l}\text { Socio-eco status } \\
\text { Poor } \\
\text { Not poor }\end{array}$ & $\begin{array}{l}858(63.8) \\
486(36.2)\end{array}$ & $\begin{array}{l}281(62.7) \\
167(37.3)\end{array}$ & $\begin{array}{l}577(64.4) \\
319(35.6)\end{array}$ & 0.547 \\
\hline $\begin{array}{l}\text { Family history of } \\
\text { breast cancer } \\
\text { positive } \\
\text { Negative }\end{array}$ & $\begin{array}{c}125(9.3) \\
1219(90.7)\end{array}$ & $\begin{array}{c}64(14.3) \\
384(85.7)\end{array}$ & $\begin{array}{c}61(6.8) \\
835(93.2)\end{array}$ & $<0.001$ \\
\hline $\begin{array}{l}\text { Smoking history } \\
\text { Ever } \\
\text { Never }\end{array}$ & $\begin{array}{c}80(6.0) \\
1264(94.0)\end{array}$ & $\begin{array}{c}44(9.8) \\
404(90.2)\end{array}$ & $\begin{array}{c}36(4.0) \\
860(96.0)\end{array}$ & $<0.001$ \\
\hline $\begin{array}{l}\text { consanguinity } \\
\text { positive } \\
\text { Negative }\end{array}$ & $\begin{array}{l}619(46.1) \\
725(53.9)\end{array}$ & $\begin{array}{l}265(59.2) \\
183(40.8)\end{array}$ & $\begin{array}{l}354(39.5) \\
542(60.5)\end{array}$ & $<0.001$ \\
\hline $\begin{array}{l}\text { Age at menarche } \\
\text { (yrs) } \\
\text { below } 13 \\
13 \& \text { above }\end{array}$ & $\begin{array}{c}273(20.3) \\
1071(79.7)\end{array}$ & $\begin{array}{c}65(14.5) \\
383(85.5)\end{array}$ & $\begin{array}{l}208 \text { ( } 23.2) \\
688(76.8)\end{array}$ & $<0.001$ \\
\hline $\begin{array}{l}\text { Age at } 1^{\text {st }} \text { FTP } \\
\text { Above } 25 \\
\text { 25\&below }\end{array}$ & $\begin{array}{c}210(15.6) \\
1134(84.4)\end{array}$ & $\begin{array}{c}94(21.0) \\
354(79.0)\end{array}$ & $\begin{array}{l}116(12.9) \\
780(87.1)\end{array}$ & $<0.001$ \\
\hline $\begin{array}{l}\text { No. of FT } \\
\text { Pregnancies } \\
\text { No. of FT } P>3 \\
\text { No. of FT } P \leq 3\end{array}$ & $\begin{array}{l}497(37.0) \\
847(63.0)\end{array}$ & $\begin{array}{l}134(29.9) \\
314(70.1)\end{array}$ & $\begin{array}{l}363(40.5) \\
533(59.5)\end{array}$ & $<0.001$ \\
\hline $\begin{array}{l}\text { Body Mass Index } \\
\mathrm{BMI} \geq 28 \\
\mathrm{BMI}<28\end{array}$ & $\begin{array}{l}389(28.9) \\
955(71.1)\end{array}$ & $\begin{array}{l}181(40.4) \\
267(59.5)\end{array}$ & $\begin{array}{l}208(23.2) \\
688(76.8)\end{array}$ & $<0.001$ \\
\hline $\begin{array}{l}\text { Age at } \\
\text { menopause(yrs) }\end{array}$ & & & & $<0.001$ \\
\hline $\begin{array}{l}45 \text { \& below } \\
\text { Above } 45\end{array}$ & $\begin{array}{l}450(59.9) \\
301(40.1)\end{array}$ & $\begin{array}{l}112(47.9) \\
122(52.1)\end{array}$ & $\begin{array}{l}338(65.4) \\
179(34.6)\end{array}$ & \\
\hline
\end{tabular}


Multiple logistic regression model was applied to the dataset comprising all women. Results of the model with the only significant interaction term (between socio economic status and age at first full term pregnancy above 25 years) are presented in Table 2. In the form of age-adjusted ORs along with the corresponding $95 \% \mathrm{Cl}$. In case of the analysis for premenopausal women with births, no interaction term was found to be statistically significant or meaningful. Multiple logistic regression model is presented with main factors only (see Table 2). For postmenopausal women, the only significant interaction term (Socioeconomic status and number of full term pregnancies more than 3) for these analyses was included in the model. Age-adjusted Odds Ratios along with $95 \%$ $\mathrm{Cl}$ are presented in Table 2.

Table 2: Significant Risk Factors for Breast Cancer in Pakistani Women

$\mathrm{P}$ Value and adjusted odds ratio $(95 \% \mathrm{Cl})$

\begin{tabular}{|c|c|c|c|}
\hline & $\begin{array}{l}\text { All women } \\
\text { with births } \\
\text { 1344) }\end{array}$ & $\begin{array}{l}\text { Premenopausal } \\
\text { (551) }\end{array}$ & $\begin{array}{l}\text { Postmenopausal } \\
\text { (751) }\end{array}$ \\
\hline Cases & 448 & 188 & 260 \\
\hline $\begin{array}{l}\text { Controls } \\
\text { Socio-economic status }\end{array}$ & $\begin{array}{l}896 \\
P=0.783\end{array}$ & $\begin{array}{l}363 \\
P=0.042\end{array}$ & $\begin{array}{l}533 \\
P=0.007\end{array}$ \\
\hline History of smoking & $\begin{array}{l}1.04(0.77- \\
P=0.000 \\
3.20(1.95-\end{array}$ & $\begin{array}{l}1.56(1.02-2.40) \\
P=0.026 \\
287(1.13-7.28)\end{array}$ & $\begin{array}{l}1.86(1.19-2.90) \\
P=0.000 \\
3.07(166-567)\end{array}$ \\
\hline $\begin{array}{l}\text { Family history of breast } \\
\text { cancer } \\
\text { Consanguineous marriage }\end{array}$ & $\begin{array}{l}P=0.000 \\
2.21(1.48 \\
P=0.000 \\
2.18(1.71\end{array}$ & $\begin{array}{l}P=0.002 \\
2.62(1.42-4.85) \\
P=0.002 \\
1.79(1.23-2.62)\end{array}$ & $\begin{array}{l}P=0.021 \\
2.03(1.11-3.68) \\
P=0.000 \\
2.85(2.01-4.06)\end{array}$ \\
\hline Age at menarche $<13$ & $\begin{array}{l}P=0.001 \\
0.58(0.42\end{array}$ & $\begin{array}{l}P=0.05 \\
0.49(0.30-0.81)\end{array}$ & $\begin{array}{l}P=0.191 \\
0.73(0.46-1.17)\end{array}$ \\
\hline No. of pregnancies $>3$ & $\begin{array}{l}P=0.000 \\
0.55(0.42\end{array}$ & $\begin{array}{l}P=0.036 \\
0.63(0.41-0.97)\end{array}$ & $\begin{array}{l}P=0.417 \\
1.28(0.70-2.33)\end{array}$ \\
\hline Body mass index $\geq 28$ & $\begin{array}{l}P=0.000 \\
2.37(1.81-\end{array}$ & $\begin{array}{l}P=0.000 \\
2.72(1.73-4.26)\end{array}$ & $\begin{array}{l}P=0.000 \\
2.22(1.53-3.22)\end{array}$ \\
\hline $\begin{array}{l}\text { Age at } 1^{\text {st }} \text { full term pregnancy } \\
>25 \text { yrs } \\
\text { Socio economic status by age } \\
\mathrm{ftp}>25\end{array}$ & $\begin{array}{l}P=0.208 \\
1.34(0.85 \\
P=0.001 \\
3.01(1.53\end{array}$ & $\begin{array}{l}P=0.069 \\
1.63(0.96-2.74) \\
N A\end{array}$ & $\begin{array}{l}P=0.000 \\
2.68(1.63-4.42) \\
\text { NA }\end{array}$ \\
\hline Age at menopause $>45$ yrs & NA & NA & $\begin{array}{l}P=0.001 \\
1.96(1.30-2.96)\end{array}$ \\
\hline $\begin{array}{l}\text { Socio economic status by No. } \\
\text { of pregnancies }>3\end{array}$ & NA & NA & $\begin{array}{l}P=0.004 \\
0.319(0.15-0.70)\end{array}$ \\
\hline
\end{tabular}

Results and Discussion:

In females, breast was the most common site of cancer accounting for one third of female cancers at Karachi [Bhurgri et al. 2000]. To see whether established high-risk factors also play a significant role in low incidence area, an attempt was made to study the role of reproductive factors in breast cancer. The data were 
restricted to parous women only [women with births]. This is the limitation of the study. For this case-control study, the interviewer was not blind to case-control status of the respondents; therefore the presence of interviewer's bias cannot be excluded.

The study showed an increasing risk for family history of breast cancer, which is in agreement with other studies (Helmrich et al., 1983; Colditz et al., 1996; Collaborative Group on Hormonal Factors in Breast Cancer, 2001). Consanguinity, a highly prevalent factor in Pakistani society, was observed to be a unique and significant risk factor for all three groups of women in this study (all women with births; premenopausal women; postmenopausal women). This factor can be further highlighted by studying the genetic aspect of consanguineous marriages. The risk of breast cancer for those in consanguineous marriage was more than double the risk of being married out of biraderi. Age at first FTP is not an independent risk factor for 'all women'. Instead for the poor with late first FTP is an independent risk factor for 'postmenopausal women'. However older age at $1^{\text {st }}$ FTP (>25 years) was shown to be a moderate risk factor for breast cancer among premenopausal women $(\mathrm{P}=0.069)$.

In case of 'all women' the risk of breast cancer for the poor women with late age at first FTP (>25years) is three times increased. Late age at first FTP is an independent risk factor for 'postmenopausal women' and a moderate risk factor of breast cancer for premenopausal women that is consistent with the findings from other studies (Helmrich et al., 1983; $\mathrm{Ng}$ et al., 1997; Tung et al., 1999; Sasaki et al. 1995). A history of early menarche (below age 13) was surprisingly observed to be protective for all women but the protection from early menarche was not observed to be statistically significant in the separate analysis of premenopausal and postmenopausal women in this study. Early menarche was a risk factor that was not statistically significant in Asian studies ( $\mathrm{Ng}$ et al., 1997; Rao et al., 1994). This sort of result for Asian studies may be due to the recall bias especially among older women. Higher age at menopause (above 45 years) was a strong determinant of breast cancer risk for postmenopausal women, which was consistent with the findings from many other studies (Negri et al., 1988; La Vecchia et al., 1992; Talamini et al., 1996). High parity (Number of Fullterm pregnancies above 3 ) was significantly protective factor for this study, which is consistent with the results from various studies (Lai et al., 1996; Talamini et al., 1996; Sasaki et al., 1995; Helmrich et al., 1983; Ramon et al., 1996). In the model for 'all women' the poor women with late age at first full term pregnancy were at three times higher risk. For premenopausal women socio-economic status was a moderate risk factor. The risk of breast cancer was higher for poor postmenopausal women. However these postmenopausal women were protected by higher number of full term pregnancies. This result is different from the results of the studies that showed the higher socio-economic status as a risk factor (Kreiger, 1990). Smokers were at increased risk of breast cancer for all the 
three groups of women in this study. The finding is similar to that observed in other studies (Morabia et al., 1996; Baron et al., 1996). Higher body mass index was observed as a significant risk factor for the three models; all women, premenopausal women; postmenopausal women. Women with $\mathrm{BMI} \geq 28$ are at twice the risk of developing breast cancer as compared to women with $\mathrm{BMl}<28$. These findings are consistent with some studies (Gilani and Kamal, 2004; Gilani, 2004; Huang et al., 1997; Ballard-Barbash \& Swanson, 1996; Ramon et al., Sasaki et al., 1995), whereas for some studies, BMI showed significant inverse and positive associations with breast cancer among premenopausal and postmenopausal women respectively (Van et al., 2000).

\section{Conclusion:}

This study of female subjects at Punjab, Pakistan, showed that the women with family history of breast cancer, consanguineous marriage and positive history of smoking were at significantly increased risk of breast cancer. Early age at menarche was not a risk factor for this population. However women with late menopause (age at menopause $>45$ years) were at higher risk of breast cancer. Higher number of pregnancies (number of full-term pregnancies $>3$ ) was a significant protective. Higher body mass index $(B M I \geq 28)$ and age at first full term pregnancy above 25 years, were directly related with the risk of breast cancer.

\section{Acknowledgement:}

We are grateful to Professor, Dr. Paolo Boffetta, Chief, Unit of Environmental Epidemiology IARC, Lyon, France, for valuable comments and suggestions on the manuscript.

We are also thankful to the oncologists, Dr. Jawaid Younis, Medical Oncologist, SKMCH; Dr. Saeeda Asghar, Directress, INMOL and Dr. Naseem llyas, Radiation oncologist, INMOL, for the help they rendered to us in the collection of data.

\section{References:}

1. Ballard-Barbash, R. and Swanson, CA., (1996), Body weight: estimation of risk for breast and endometrial cancers, "Am J Clin Nutr", 63 (suppl), pp. 437-441.

2. Baron, JA., Newcomb, PA., Longnecker, MP., Mittendrof, R., Storer, BE., Clapp, RW., Bogdan, G. and Yuen, J., (1996), Cigarette smoking and breast cancer, "Cancer Epidemiol Biomarkers Prev", 5:5, pp. 399-403.

3. Bhurgri, Y., Bhurgri, A., Hasan, SH., Zaidi, SHM., Rahim, A., Sankarnarayan, R., Parkin, DM., (2000), Cancer incidence in Karachi, Pakistan: First results from Karachi cancer registry, "Int. J Cancer", 85, pp. 325-29.

4. Breslow, N.E. and Day, N.E., (1980). Statistical methods in cancer 
Risk factors for breast cancer for women in Punjab, Pakistan: Results from a case-control study

research. Vol.1. The analysis of case-control studies. IARC Scientific Publications 32, International Agency for Research on Cancer, Lyon, France.

5. Brinton, LA., Schairer, C., Hoover, RN., Fraumeni, JF. Jr., (1988). Menstrual factors and risk of breast cancer. Cancer Invest, 6: 245-54.

6. Choi, NW., Howe, GR., Miller, AB., Mathews, V., Morgan, RW., Munan, L., Burch, JD., Feather, J., Jain, M. and Kelly, A., (1978), An epidemiologic study of the breast cancer", "Am J Epidemiol.", 107, pp. 510-521.

7. Colditz, GA., Rosner, BA. and Speizer FE., (1996), R isk factors for breast cancer according to family history of breast cancer, "J Natl Cancer Inst.", 88:6, 365-71.

pp.

8. Coleman, MP., Esteve, J., Damiecki, P., Arslan, A., Renard, H., editors. (1993), Trends in cancer incidence and mortality, Lyon; IARC Scientific Pub. No.121.

9. Collaborative Group on Hormonal Factors in Breast Cancer (2001), Familial Breast Cancer, "Lancet”, 358, pp 1389-1399.

10. Gilani, G.M. (2004), S tatistical Aspects of E pidemiology of Breast Cancer in P unjab, Pakistan. Unpublished Ph.D. Thesis.

11. Gilani, G.M. and Kamal, S. (2004), Risk Factors for Breast Cancer in Pakistani Women aged less than 45 years. Annals of Human Biology, Vol.31, 398-407.

No.4,

12. Helmrich, SP., Shapiro S., Rosenberg, L., Kaufman, DW., Slone, D., Bain C., Miettinen, O., Stolley PD., Rosenshein, NB., Knapp, RC., Leavitt, T., Schottenfeld, D., Engle, RL. and Levy M., (1983), R isk factors for breast cancer, "Am J Epidemiol", 117, pp 35-45.

13. Hsieh, C-C., Trichopoulos, D., Katsouyanni, K. and Yuasa, S., (1990), Age at menarche, age at menopause, height and obesity as risk factors for breast cancer: association and interactions in an international case-control study, "Int J Cancer", 46, pp 796-800.

14. Huang, Z., Hankinson, SE., Colditz, GA., Stampfer, MJ., Hunter, DJ., Manson, JE., Hennekens CH, Rosner B, Speizer FE, Willett WC., (1997). Dual effects of weight and weight gain on breast cancer risk. JAMA, 278: 1407-11.

15. Kampert, JB., Whittemore, AS. and Paffenbarger, RS. Jr., (1988), Combined effect of childbearing, menstrual events and body size on agespecific breast cancer risk, "Am J Epidemiol", 128, pp 962-979.

16. Kreiger N. (1990), Social class and the black / white crossover in the agespecific incidence of breast cancer: a study linking census-derived data to population-based registry records, "Am J Epidemiol”, 131, pp 804-14.

17. Kvale, G. and Heuch, I., (1988). Menstrual factors and breast cancer risk. Cancer, 62: 1625-31.

18. La Vecchia, C., Negri, E., Bruzzi, P., Dardanoni, G., Decarli, A., Franceschi, S., Palli, D., Talamini R., (1992). The role of age at menarche 
Ghausia Masood Gilani, Shahid Kamal, Syed Aamir Masood Gilani

and at menopause on breast cancer risk: combined evidence from four case-control studies. Ann Oncol, 3: 625-9.

19. Lai, F-M., Chen, P., Ku, H-C., Lee, M-S., Chang, S-C, Chang, T-M. and Liou, S-H., (1996), A case-control study of Parity, Age at first full term pregnancy, breast-feeding and breast cancer in Taiwanese women. Proceedings of the National Science Council, ROC, part B: Life Sciences", Vol. 20, No. 3, pp 71-77.

20. Morabia, M., Bernstein, S. Heritier and Khatchatrian. N. (1996), Relation of breast cancer with passive and active exposure to tobacco smoke, "Am J Epidemiol." 143: 9, 918-28.

21. Negri, E., La Vecchia, C., Bruzzi, P., Dardanoni, G., Decarlj, A., Palij, D., Parazzini, F., Turco, MR., (1988). Risk factors for breast cancer: pooled results from three Italian case-control studies. Am J Epidemiol, 128: 120715.

22. Ng, EH. Gao, F. Ji, CY. Ho JH. and Soo, KC. (1997), Risk factors for breast carcinoma in Singaporean Chinese women, "Cancer", 80, pp 72531.

23. Ramon, JM., Escriba, JM., Casas, I., Benet, J., Iglesias, C., Gavalda, L., Torras, G. and Oromi, J., (1996). Age at first full term pregnancy, loctation and parity and risk of breast cancer: A case-control study in Spain, Eur $\mathrm{J}$ of Epibemiology, 12: 449-53.

24. Rao, DN., Ganesh B. and Desai PB., (1994), Role of reproductive factors in breast cancer in a low-risk area: a case-control study, "Br. J Cancer", 70 , 129-32.

25. Romieu, M., Hernadez-Avila, E., Lazcano, L., Lopez, R., Romero-Jaime (1996), Breast cancer and lactation history in Mexican women, "Am J Epidemiol.", 143, pp 543-52.

26. Sasaki, R., Ito, Y., Ogawa, H., Matsuyama, M., Suzuki, S. and Yagyu K., (1995), Case-control study on breast cancer in Madras, India: finding on diet, reproductive factors and anthropometric measurement (Meeting abstract), “Jpn J Cancer Res”, 7(10), p 708.

27. Talamini, R., Franceschi, S., La Vecchia, C., Negri, E., Brosa L., Montella, M., Falcini, F., Conti E. and Rossi C., (1996), The role of reproductive and menstrual factors in cancer of the breast before and after menopause, "Europ J Cancer", 32A, pp 303-310.

28. Tung, HT., Tsukuma, H., Tanaka, H., Kinoshita, N., Koyama, Y., Ajikl, W., Oshima A. and Koyama H., (1999), Risk factors for breast cancer in Japan, with special attention to Anthropometric measurements and reproductive history, "Jpn J Clin Oncol." 29 (3) pp 137-146.

29. Van den Brandt, PA., Spiegelman, D., Yaun, SS., Adami, HO., Beeson, L., Folsom, AR., Fraser, G., Goldbohm, RA., Graham, S., Kushi, L., Marshall, JR., Miller, AB., Rohan, T., Smith-Warner, SA., Speizer, FE., Willett, WC., Wolk A. and Hunter DJ., (2000), Pooled analysis of prospective cohort studies on height, weight and breast cancer risk, "Am J Epidemiol." 152 (6), pp 514-27. 
Risk factors for breast cancer for women in Punjab, Pakistan: Results from a case-control study

30. Yousuf, F. and Jaffery, N.A., (1985), On the incidence of malignant tumors of breast among females, Pakistan, "Pakistan J. Med. Res." 24: 3, pp 123-127.

31. Zhu, K., Caulfield, J., Hunter, S., Roland, C.L., Payne-Wilks, K. and Texter, L., (2005), Body Mass Index and Breast Cancer Risk in African American Women, "Ann Epidemiol”, 15: pp 123-128. 